\title{
Prevalence and antimicrobial susceptibility pattern of Coagulase-negative Staphylococcus
}

\author{
Dr. E. Shamsadh Begum MD, Dr. N. Anbumani MD, Ph D, Dr. J. Kalyani MD, Dr. M. Mallika MD, \\ Department of Microbiology, Sri Ramachandra University, Porur, Chennai-600116
}

\section{A B STRACT}

Background: The vast majority of infections assumed to be caused by Coagulase-negative Staphylococcus (CoNS) are a significant consequence of hospitalization. Current antibiotic-prescribing practices, including preoperative antibiotic prophylaxis, have led to the selection of antibiotic-resistant organisms. The purpose of the present study is to provide a current scenario, species distribution in clinical specimens and antimicrobial susceptibility testing, mainly to screen for methicillin resistance, multi-drug resistant strains. Methodology: Total 113 isolates of Coagulase- negative Staphylococci were isolated from clinical specimens over a 6 month period in a non consecutive non random manner. Antimicrobial resisitance pattern to 20 antimicrobial agents were performed Results: Coagulase-negative Staphylococci consisting of 10 different species were isolated. Staphylococcus epidermidis (49), Staphylococcus haemolyticus (19), Staphylococcus hominis (11) were the most commonly isolated species. Antimicrobial susceptibility pattern revealed that they were all universally sensitive to vancomycin and linezolid. Methicillin resistance was noted among $48 \%$ of the isolates. Maximum resistance was seen with penicillin (91\%) and least with Teicoplanin(3\%) Conclusion: CoNS are a significant cause of nosocomial bacteremia and their susceptibility to beta-lactamase-stable penicillins is unpredictable. Hence the methicillin resistant CoNS which are also multidrug resistant act as a reservoir for drug resistance in hospitals. Low level glycopeptide resistance encountered in recent years limits its use. For all these reasons, accuracy and promptness in the detection of resistance pattern is of key importance to ensure appropriate antibiotic treatment in infected patients as well as control the spread of resistance in hospital environments.

Key words: Coagulase-negative Staphylococci, antimicrobial resistance

\section{INTRODUCTION}

Coagulase-negative staphylococcus (CoNS) is a heterogeneous group of adaptable and opportunistic pathogens whose adaptability to persist and multiply in a variety of environments causes a wide spectrum of diseases in humans. Often identification of Staphylococcus is limited to a rapid screening test for Staphylococcus aureus and non Staphylococcus aureus isolates are simply designated as CoNS.

We should not disregard any of these organisms until their clinical significance is resolved and since they are

Address for correspondence: Dr. E. Shamsadh Begum, MD

Assistant Professor, Department of Microbiology

Sri Ramachandra University, Porur, Chennai-600116

E-mail: shamsadh@gmail.com/shamsadh@live.com

DOI: 10.5530/ijmedph.4.2011.14 frequently opportunistic pathogens, we may never completely resolve the question of significance.

Multiple resistances to antibiotics have been reported in many CoNS isolates, making infections they cause difficult to treat ${ }^{[1-5]}$. However, despite the development of multiple resistances and the growing importance as nosocomial pathogens, not all species are pathogenic. It is, therefore, important to speciate CoNS isolates from clinical materials ${ }^{[6]}$.

After admission to the hospital and especially after exposure to multiple courses of antibiotics, or surgical prophylaxis, patients become colonized with multi-drug resistant strains and other more resistant CoNS species such as Staphylococcus haemolyticus. This has led to use of glycopeptides in high risk patients and thereby its low level resistance in hospital strains ${ }^{[7]}$. The selection of glycopeptide resistance and the potential transmission 
of such resistance between species have led to call for restricted use of glycopeptides.

The objective of this study was to determine the incidence of CoNS species from different clinical samples and their resistance patterns so as to provide these data on the prevailing strains in the hospital.

\section{MATERIALS AND METHODS}

Bacterial strains: 113 strains of CoNS recovered from cultures of clinical specimens over a period of six months from November 2004 to April 2005 from hospitalized patients were studied. Coagulase-negative Staphylococcus was identified based on the conventional scheme of identification proposed by Kloos and Schleifer ${ }^{[8]}$. Clinical significance was based on repeated isolation of the same organism from the same site.

Antimicrobial susceptibility testing was done on MuellerHinton agar according to standard procedures ${ }^{[9]}$. Methicillin resistance was screened by both oxacillin and cefoxitin discs. Staphylococcus aureus ATCC 25923 and Staphylococcus epidermidis ATCC 12228 strains were used as controls. Results were interpreted as per CLSI guidelines ${ }^{[10]}$.

\section{RESULTS}

The distribution of 113 CoNS isolates according to species and clinical material sources are presented in Table 1. Data showed S.epidermidis to be the most common CoNS species $(n=55)$ and blood cultures yielded the highest number of isolates $(n=30)$. ICU was the most important source of CoNS isolates contributing 44 isolates followed by post operative surgical wards.

\section{RESISTANCE TO ANTIMICROBIALS}

The resistance patterns of the isolates to twenty different antibiotics are presented in Table 2.
Among the $\beta$-lactams, maximum resistance was seen with penicillin (91\%) followed by ampicillin (72\%). Resistance to methicillin was seen in $48 \%$ of the CoNS isolates. With the cephalosporins, $68 \%$ were resistant to cephalexin and $65 \%$ to cephotaxime.

In the macrolides group, $83 \%$ of the isolates showed resistance to erythromycin. While within the fluoroquinolones, resistance to ciprofloxacin and ofloxacin were found in $60 \%$ and $50.4 \%$ of the CoNS isolates respectively.

With reference to aminoglycosides, higher percentage $(80 \%)$ of resistance was seen for gentamicin when compared to amikacin (48.6\%).Cotrimaxazole and nitrofurantoin were used only for urinary isolates and $75 \%$ were resistant to both the drugs. $42 \%$ of the isolates were resistant to rifampicin.

While all CoNS strains were sensitive to oxazolidones (linezolid), with glycopeptides $100 \%$ sensitivity was found to vancomycin and only $97.3 \%$ to teicoplanin. $64 \%$ of S.epidermidis, $78 \%$ of S.baemolyticus and $50 \%$ of S.saprophyticus were multiple resistant to 3 or more of the following group of agents: $\beta$-lactams, aminoglycosides, macrolides, quinolones and trimethoprim. (Table 3)

\section{DISCUSSION}

This study showed that $S$. epidermidis was the most common CoNS species comprising $43 \%$ of all isolates similar to that of other reports ${ }^{[1-16]}$. CoNS was reported as an important cause of blood stream infections and the second most common source after wound swabs in a hospital in Lebanon and Kuwait ${ }^{[17-18]}$.

Although there exists about 33 CoNS species, only a few of them have been associated with an increase in hospital acquired infections due to the use of invasive elements ${ }^{[19]}$. In a survey with dialysis patients carried out in 2002, 40 to $60 \%$ of the infections were caused by CoNS species.

\begin{tabular}{|c|c|c|c|c|}
\hline Species & Exudate & Blood & Urine & Tota \\
\hline Staphylococcus epidermidis & 11 & 30 & 8 & 49 \\
\hline Staphylococcus haemolyticus & 5 & 9 & 5 & 19 \\
\hline Staphylococcus hominis & 4 & 4 & 3 & 11 \\
\hline Staphylococcus cohnii & 3 & 4 & 2 & 9 \\
\hline Staphylococcus capitis & 3 & 3 & 1 & 7 \\
\hline Staphylococcus warneri & 5 & 1 & 1 & 7 \\
\hline Staphylococcus simulans & 3 & 1 & 1 & 5 \\
\hline Staphylococcus saprophyticus & 0 & 1 & 3 & 4 \\
\hline Staphylococcus lugdunensis & 0 & 1 & 0 & 1 \\
\hline Staphylococcus xylosus & 0 & 1 & 0 & 1 \\
\hline Total & 34 & 55 & 24 & 113 \\
\hline
\end{tabular}




\begin{tabular}{lcc}
\multicolumn{3}{l}{ Table 2: Resistance to Antimicrobial Agents } \\
\hline $\begin{array}{l}\text { Antimicrobial } \\
\text { agents }\end{array}$ & $\begin{array}{c}\text { Total No of } \\
\text { isolates }(\mathbf{N}=113)\end{array}$ & Percentage \% \\
\hline Penicillin $\mathrm{G}(10 \mathrm{units})$ & 103 & 91.1 \\
Ampicillin $(10 \mu \mathrm{g})$ & 82 & 72.5 \\
Cloxacillin $(5 \mu \mathrm{g})$ & 72 & 63.7 \\
Oxacillin $(1 \mu \mathrm{g})$ & 54 & 47.7 \\
Cephalexin $(30 \mu \mathrm{g})$ & 77 & 68.1 \\
Cefotaxime $(30 \mu \mathrm{g})$ & 73 & 64.6 \\
Cefoxitin $(30 \mu \mathrm{g})$ & 57 & 50.4 \\
Gentamicin $(5 \mu \mathrm{g})$ & 90 & 79.6 \\
Amikacin $(30 \mu \mathrm{g})$ & 55 & 48.6 \\
Tobramicin $(5 \mu \mathrm{g})$ & 53 & 46.9 \\
Norfloxacin $(10 \mu \mathrm{g})$ & 59 & 52.2 \\
Ciprofloxacin $(5 \mu \mathrm{g})$ & 68 & 60.1 \\
Ofloxacin $(5 \mu \mathrm{g})$ & 57 & 50.4 \\
Erythromycin $(15 \mu \mathrm{g})$ & 94 & 83.1 \\
Rifampicin $(5 \mu \mathrm{g})$ & 48 & 42.4 \\
Cotrimaxazole & 85 & 75.2 \\
Nitrofurantoin $(300 \mu \mathrm{g})$ & 85 & 75.2 \\
Linezolid $(30 \mu \mathrm{g})$ & 0 & 0 \\
Vancomycin $(30 \mu \mathrm{g})$ & 0 & 0 \\
Teicoplanin $(5 \mu \mathrm{g})$ & 3 & 2.65 \\
No resistance & 8 & 7 \\
\hline
\end{tabular}

Table 3: Multiple drug resistance of CoNS

\begin{tabular}{lcc}
\hline CoNS Species & Number tested & $\begin{array}{c}\text { Number resistant to } \\
\mathbf{3} \text { group of agents \% }\end{array}$ \\
\hline S. epidermidis & 49 & $(16) 64 \%$ \\
S. haemolyticus & 19 & $(15) 78 \%$ \\
S. hominis & 11 & $(4) 80 \%$ \\
S. cohnii & 9 & $(4) 100 \%$ \\
S. capitis & 7 & $(1) 100 \%$ \\
S. warneri & 7 & 0 \\
S. simulans & 5 & 0 \\
S. saprophyticus & 4 & 0 \\
S. lugdunensis & 1 & 0 \\
S. xylosus & 1 & 0 \\
Total & 113 & $(40) 65 \%$ \\
\hline
\end{tabular}

In another study among catheter related blood stream infections $-96 \%$ were S. epidermidis ${ }^{[21]}$. Similarly in another study, of the isolated CoNS strains, 51\% were S.epidermidis, $18 \%$ S.baemolyticus, $16 \%$ S. saprophyticus ${ }^{[22]}$. The results obtained in our study were similar coinciding with the fact that the most frequently isolated CoNS strain was S.epidermidis followed by S.haemolyticus.

Highincidence of methicillin resistancein the Staphylococci is a common problem in many institutions ${ }^{[1,3,12]}$. The $48 \%$ incidence of methicillin resistance observed in this study was almost equal to that noted in S.aureus, isolated in the same hospital during the same study period.

Methicillin resistance in Staphylococci necessitated the use of the glycopeptides vancomycin and recently teicoplanin for the empiric treatment of serious Staphylococcal infections ${ }^{[2,6,15]}$. Subsequent resistance to vancomycin was reported in some strains of S. haemolyticus ${ }^{[23-25]}$. Staphylococcus baemolyticus is known to be unique among Coagulasenegative Staphylococci in being predisposed to develop glycopeptide resistance and especially to teicoplanin for which MICs are increased ${ }^{[26]}$. Three of our S. haemolyticus isolates expressed resistance to teicoplanin.

\section{CONCLUSION}

The increasing importance of CoNS nowadays may be due in part to the growing appreciation of this group of organisms as opportunistic pathogens and to the increase in the use of transient or permanent medical devices, such as intravascular catheters and prosthetic devices, in seriously ill and immunocompromised patients (i.e., intensive care patients, premature newborns, and cancer and transplant patients). CoNS infections often can be life-threatening in these patients.

Although Staphylococcus epidermidis accounts for most CoNS infections, many other species have been identified in association with human infections. CoNS species identification, which is still difficult for most clinical laboratories, is necessary in order to establish epidemiological trends, confirm treatment failures, or determine the cause of specific infections.

\section{REFERENCES}

1. Sanzen L, Walder M. Antibiotic resistance of Coagulase negative Staphylococci in an orthopaedic department. J Hosp Infect 1988;12:103-108.

2. Christensen GD. The sticky problem of Staphylococcus epidermidis sepsis Hosp.Pract. Sept 1993;30:27-38.

3. Pfaller MA, Herwaldt LA. Laboratory, Clinical, and Epidemiological Aspects of Coagulase-Negative Staphylococci. Clin Microbiol Rev 1988; 1:281-299.

4. Larson RA, Burke JP. The epidemiology and risk factors for nosocomial catheter associated bacteriuria caused by Coagulase negative Staphylococci. Infect Contr 1986;7:212-215.

5. Christensen GD, Simpson WA, Bisno AL, Beachey EH.Adherence of slime-producing strains of Staphylococcus epidermidis to smooth surfaces. Infect Immun 1983;37:318-326.

6. Archer GL. Coagulase negative Staphylococci in blood cultures. The clinicians dilemma Editorial. Infect Contr 1985;6:477-478.

7. Sanyal D, Johnson AP, George RC, Edwards R, Greenwood D In-vitro characteristics of glycopeptide resistant strains of Staphylococcus epidermidis isolated from patients on CAPD J. Antimicrob. Chemother. 1993 32(2):267-278.

8. Kloos WE, Schleifer KH. Simplified scheme for routine identification of human Staphylococcus species. J Clin Microbiol 1975;1:82-88.

9. Milles RS, Amyes SGB. Laboratory control of antimicrobial therapy in Mackie and McCartney, Practical Medical microbiology. 14th ed. Edited by Collee JG, Fraser AG, Marmion P, Simmons A .Churchill Livingstone 1999:151-157.

10. Wayne PA, NCCLS. National Committee for clinical laboratory standards. Performance standards for antimicrobial disk susceptibility tests. 8th ed Approved standard M2-A8, 2003. 
11. Kirchhoff LV, Sheagren JN. Epidemiology and clinical significance of blood cultures positive for Coagulase- negative Staphylococci. Infect. Contr. 1985;6:479-486.

12. Kloos WE, Bannermann TL. Update on clinical significance of Coagulase negative Staphylococci. Clin Microbiol Rev 1994;7:117-140.

13. Deighton MA, Franklin JC, Spicer WJ, Balkau B. Species identification, antibiotic susceptibility and slime production of Coagulase negative Staphylococci from clinical specimens. Epidem Infect 1988;101:99-113.

14. Fidalgo S, Vazquez F, Mendoza MC, Perez F, Mendez FJ. Bacteremia due to Staphylococcus epidermidis: Microbiologic, epidemiologic, clinical and prognostic features. Rev Infec Dis 1990;12:520-528.

15. Jones JW, Scott RJD, Morgan J, Pether JVS. A Study of Coagulase negative staphylococci with reference to slime production, adherence, antibiotic resistance patterns and clinical significance. J Hosp Infect 1992;22:217-227.

16. Sidebottom DG, Freeman JT, Platt R, Epstein MF, Goldman DA. Fifteen years experience with bloodstream isolates of Coagulase-negative staphylococci in neonatal intensive care. J Clin Microbiol 1988;26:713-718.

17. Udo EE, Jacob LE, Chugh TD. 1995. Antimicrobial resistance of Coagulase negative staphylococci from a Kuwait hospital. Microbial Drug Resist 1:315-320.

18. Araf GF, Uwaydah MM, Alami SY. Antimicrobial susceptibility pattern of bacterial isolates at the American University Medical Center in Lebanon. Diagn Microbiol Infect Dis. 1994;20:151-158.

19. Sharon J Peacock. Staphylococcus in Topley and Wilson's Microbiology and microbial infections.10th ed. Edited by Arnold Hodder, Murray Patrick R, Barry Holmes and Hazil M Aucken 2005:771-832.
20. Anthony Finelli, Lori L. Burrows, Frank A. DiCosmo, Valerio DiTizio, Selva Sinnadurai, Oreopoulos Dimitrios G. Khoury Antoine E. Colonization-resistant antimicrobial-coated peritoneal dialysis catheters: evaluation in a newly developed rat model of persistent Pseudomonas aeruginosa peritonitis. Perit Dial Internat 2002;22:27-31.

21. Worthington T, Lambert PA, Elliot TS. Is hospital-acquired intravascular catheter-related sepsis associated with outbreak strains of coagulasenegative Staphylococci? J Hos Infect 2000;46:130-134.

22. De Paulis A, Predari S, Chazarreta C, Santoiani J. Five-test simple scheme for species-level identification of clinically significant CoagulaseNegative Staphylococci. J Clin Microbiol 2003;41:1219-1224.

23. Johnson AP, Uttley AH, Woodford N, George RC. Resistance to vancomycin and teicoplanin: an emerging clinical problem. Clin Microbiol Rev 1990;3:280-291.

24. Schwalbe RS, Stapleton JT, Gilligan PH. Emergence of vancomycin resistance in Coagulase-negative staphylococci. N Engl J Med 1987; 316:927-931

25. Veach LA, Pfaller MA, Barrett M, Koontz FP, Wenzel RP. Vancomycin resistance in Staphylococcus haemolyticus causing colonization and bloodstream infection. J Clin Microbiol 1990;28:2064-2068.

26. Biavasco Francesca, Vignaroli Carla, Lazzarini Raffaella, Varaldo Pietro E. Glycopeptide Susceptibility Profiles of Staphylococcus haemolyticus bloodstream Isolates Antimicrobial agents Chemo 2000;44:3122-3126. 